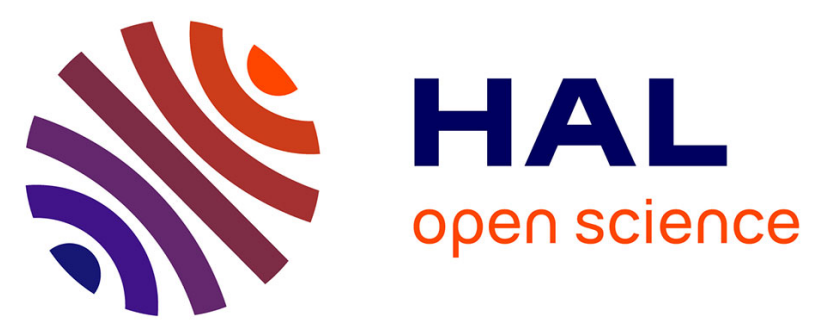

\title{
Relevance of an at-site flood frequency analysis method for extreme events based on stochastic simulation of hourly rainfall.
}

\author{
P. Arnaud, P. Cantet, Y. Aubert
}

\section{- To cite this version:}

P. Arnaud, P. Cantet, Y. Aubert. Relevance of an at-site flood frequency analysis method for extreme events based on stochastic simulation of hourly rainfall.. Hydrological Sciences Journal, 2016, 61 (1), pp.36-49. 10.1080/02626667.2014.965174 . hal-01528679

\section{HAL Id: hal-01528679 \\ https://hal.science/hal-01528679}

Submitted on 29 May 2017

HAL is a multi-disciplinary open access archive for the deposit and dissemination of scientific research documents, whether they are published or not. The documents may come from teaching and research institutions in France or abroad, or from public or private research centers.
L'archive ouverte pluridisciplinaire HAL, est destinée au dépôt et à la diffusion de documents scientifiques de niveau recherche, publiés ou non, émanant des établissements d'enseignement et de recherche français ou étrangers, des laboratoires publics ou privés. 
1 Title: Relevance of an at-site flood frequency analysis method for extreme events based on

2 stochastic simulation of hourly rainfall.

3 Titre: Pertinence d'une méthode de prédétermination des crues basée sur la simulation stochastique

4 de pluies horaires

Patrick ARNAUD, Irstea - National Research Institute of Science and Technology for Environment and Agriculture, 3275 Route de Cézanne, CS 40061, Aix-en-Provence, France3275 Route de Cézanne, CS 40061, Aix-en-Provence, France. +33442669946, patrick.arnaud@irstea.fr Philippe CANTET, Irstea - National Research Institute of Science and Technology for Environment and Agriculture, 3275 Route de Cézanne, CS 40061, Aix-en-Provence, France. +33442669947, philippe.cantet@irstea.fr Yoann AUBERT, Hydris Hydrologie, 5 Avenue du grand chêne, 34270 Saint-Mathieu-de-Tréviers, France, +33467660214, yoann.aubert@ hydris-hydrologie.fr

Corresponding author: Patrick ARNAUD

\section{Abstract:}

Extreme events are rarely observed, so their analysis is generally based on observations of more frequent values. The relevance of flood frequency analysis (FFA) method depends on its capability to estimate the frequency of extreme values with reasonable accuracy using extrapolation. A FFA method based on stochastic simulation of flood event is assessed based on its reliability and stability. For such an assessment, different training/testing decompositions are performed for a set of data from more than 1,000 gauging stations. We showed that the method enables relevant "predictive" estimates, e.g. by assigning correct return periods to the record values that are systematically absent in calibration data sets. The model is also highly stable vis-a-vis the sampling. This characteristic is linked to the use of regional statistical rainfall data and a simple rainfall-runoff model that requires calibrating only one parameter.

\section{Résumé:}

Les événements extrêmes sont par nature rarement observés, c'est pourquoi leur estimation est généralement basée sur l'observation de valeurs plus courantes. La pertinence d'une méthode de prédétermination des événements extrêmes dépend donc de sa capacité à raisonnablement extrapoler les distributions de fréquences vers les valeurs extrêmes. Dans cette étude, une méthode de prédétermination de crues basée sur la simulation de scénarios de pluies horaires, est évaluée sur sa capacité à produire des estimations justes et stables. Cette évaluation s'appuie sur différents tests d'échantillonnage sur les périodes de calage et de validation, appliqués sur un jeu de données conséquent (plus de 1000 stations). Nous montrons que la méthode est capable de fournir une estimation pertinente sur les événements extrêmes bien que ceux-ci soit systématiquement ôtés de la période de calage. La méthode montre aussi une grande stabilité face à l'échantillonnage. Cette caractéristique est liée à l'utilisation d'une information statistique régionale sur la pluie et à la simplicité de la modélisation hydrologique paramétrée par un seul paramètre.

40 Keywords: extreme events, stochastic model, flood frequency analysis.

41 Mots clés: événements extrêmes, modèle stochastique, prédétermination des crues

\section{Introduction}


To plan a risk prevention strategy, it is necessary to examine the hydrometeorological variability in an entire region. This analysis has many operational applications, e.g. mapping flood-prone areas (European Flood Directive 2007/60/EC), designing hydraulic structures (Lavabre et al. 2009), and defining the frequency of hydrometeorological events for natural disaster assessments or alert methods (Javelle et al. 2010). Hydrologists have developed many flood frequency analysis (FFA) methods. The development of these methods is often influenced by the availability of observation data and by the specific hydrometeorological characteristics. In Europe, the FloodFreq COST ES0901 Action (http://www.cost-floodfreq.eu/) has identified most well-know FFA methods, including methods which enable an initial estimate of rainfall risk used as input for more or less empirical rainfall-runoff modelling approaches (Willems et al. 2012), and those which estimate hydrological risk directly from hydrometric data (Castellarin et al. 2012). All these methods are generally presented in Hydrology reference books (Chow et al. 1988, Lang and Lavabre 2007, Llamas 1993).

Broadly speaking, purely statistical methods are to fit a probability distribution law directly to the empirical frequency distribution of the hydrological variable studied. The choice of probability distributions used to estimate flood flows is distributions based on the Extreme Value Theory (Coles 2001). The probability distributions used the most often in flood frequency analysis include the Generalized Extreme Value (GEV) distribution (Hosking and Wallis 1993), the Generalized Pareto (GP) distribution and the Three-Parameter Lognormal (TPLN) distribution. These three probability distributions are used on site in favourable observation conditions (Klemes 1993). At sites where observation data are inadequately gauged or nonexistent, regional approaches are used, namely a regional flood frequency analysis (RFFA). These include values observed on neighbouring sites to increase the size of the sample of observations, using either the index flood method (Darlymple 1960) or other RFFA (Hosking and Wallis 1993, Stedinger and Tasker 1985, Hosking and Wallis 1997, Ribatet et al. 2007, Merz and Blöschl 2005)). Extrapolating frequency distributions to extreme values is still problematic, however, because hydrological phenomena are strongly nonlinear (Katz et al. 2002). Calibrating a model based on frequent observations does not guarantee extrapolation to extreme values. This is why certain purely statistical methods rely on estimation of rainfall variability to extrapolate flow probability distribution (Guillot and Duband 1967, Margoum et al. 1994). By construction, simulation approaches use rainfall data. They have been developed especially to fulfil the temporal data requirements associated with design floods (Eagleson 1972). Such approaches mimic some of the statistical properties of rainfall observations and the rainfall/runoff relationship in order to generate rainfall and runoff series that can be used subsequently as observed series. These simulated series, which are becoming increasingly common, are then used to extract the desired hydrological characteristics (i.e. quantiles), and can also be used to test the failure of hydraulic structures when subjected to extreme events (Lavabre et al. 2010). Simulation approaches are used more and more ( $\mathrm{Li}$ et al. 2014). Models differ according to the type of rainfall generator or rainfall-runoff model used (Blazkova and Beven 2004, Cadavid et al. 1991, Onof et al. 2005, Shen et al. 1990), a summary of which is presented in the article (Boughton and Droop 2003). In France, there are two simulation approaches, one developed by Electricité de France (EdF) (Paquet et al. 2013), and the other, by Irstea (Arnaud and Lavabre 2002, Aubert et al. 2013) (SCHADEX and 
A complete nationwide database on the estimation of flood flow quantiles has been produced due to the implementation of the SHYREG method (Aubert et al. 2013, Organde et al. 2013).

This method was also evaluated in comparison with other FFA and RFFA methods, as part of a nationwide research project (ANR Extraflo project, https://extraflo.cemagref.fr) (Kochanek et al. 2013). The project involved establishing evaluation indexes to assess method relevance. This article presents (\$2) the SHYREG method (calibration of hourly rainfall generator and hydrological model), (\$3) data and stability and reliability indexes and (\$4) its reliability and stability performance over a broad sampling of data, (\$5) before discussing the method's inherent characteristics that lead to such performance.

\section{The SHYREG method}

\subsection{The principle}

The SHYREG method is a simplified version of the SHYPRE (Simulated HYdrographs for flood PRobability Estimation) method (Arnaud and Lavabre 2002), adapted for the purposes of regional flood flow studies. Both these frequency analysis methods are based on process simulation. SHYPRE was first developed to simulate catchment flood scenarios. It couples a stochastic hourly rainfall generator (Arnaud and Lavabre 1999, Cernesson et al. 1996, Arnaud et al. 2006, Cantet et al. 2010, Cantet and Arnaud 2014) with a rainfall-runoff model. In this way the model generates a set of flood hydrographs, which can then be used to empirically deduce the frequency distribution of peak and maximum mean flows over different durations. The analysis of this even-based of peak approach focuses on hourly rainfall events selected from daily criteria (all daily rainfalls of the event are greater than $4 \mathrm{~mm}$ and one of them must exceed at least $20 \mathrm{~mm}$ ). In France, the number of such events was mapped and varies between 3 and 25 events per year. In order to generate 1,000 years of flood events, we generate the number of events per year for each year (using the Poisson distribution law) and the associated independent rainfall events. These are transformed into flood events, which are associated to a simulation of 1,000 year period.

The SHYREG (SHYpre REGionalised) method was developed after the SHYPRE method, and is based on the same principle, but was adapted to simplify the initial approach and thus facilitate its regionalization (Aubert et al. 2013, Organde et al. 2013) in order to estimate flood frequencies on un-gauged basins. It is implemented in two steps:

- Regionalizing the hourly rainfall generator. The rainfall model was regionalized for all French territory, including the tropical islands of Reunion (Aubert et al. 2014), Martinique and Guadeloupe. Its regional application is based on the use of daily rainfall data, which are more broadly available than hourly data. This regionalization process is detailed in a methods guidebook and articles (Arnaud and Lavabre 2010, Arnaud et al. 2008b). It relies on the mapping of three characteristic daily rainfall variables (for intensity, duration, and frequency) to calibrate the hourly rainfall generator. These three variables, estimated for two seasons ${ }^{1}$, were determined based on 2,812 rain gauge stations on French territory and then mapped, taking local environmental and topographical characteristics into account (Arnaud

\footnotetext{
${ }^{1}$ The hourly rainfall generator is calibrated for two seasons: the summer (from June to November) and the winter (from December to May). By this way, we distinguish the long events with low rainfall intensity and the short events characterized by high quantity of rainfall.
} 
et al. 2008a). The regionalized parameters are used to parameterize the hourly rainfall generator and the hourly rainfalls simulated are transformed into flood according to hydrological model. The simulated hourly rainfall time series also serve to establish a rainfall risk database (intensity-duration-frequency curves for the entire territory).

- Regionalizing the rainfall-runoff model. We chose to convert hourly rainfall into flood flow at a pixel resolution of $1 \mathrm{~km}^{2}$. The use of pixels is necessary because of the point-wise nature of rainfall generator (this is not a rainfall field/spatial generator), while also simplifying the rainfall-runoff model. Regionalization is a two-phase process. First, the rainfall generator parameters are set to the local values of the pixel, then hourly rainfall events over the pixel are generated and transformed into flood events through with a simplified rainfall-runoff model (described below). Simplifying the model involves using a single parameter. The flood scenarios are used to obtain flow quantiles for each $\mathrm{km}^{2}$ (called

This article presents the performance of the local version of SHYREG, calibrated on gauged catchments. The focus of the research is not the regionalization process, but rather the calibration of the method for a wide range of catchments and the resultants of the quantile estimation.

\subsection{Method calibration}

Calibrating the SHYREG method consists in determining which rainfall-runoff model parameters should be used in order to most closely match the frequency distributions for the flows observed at gauged stations. The calibration steps are described in Fig. 1. 

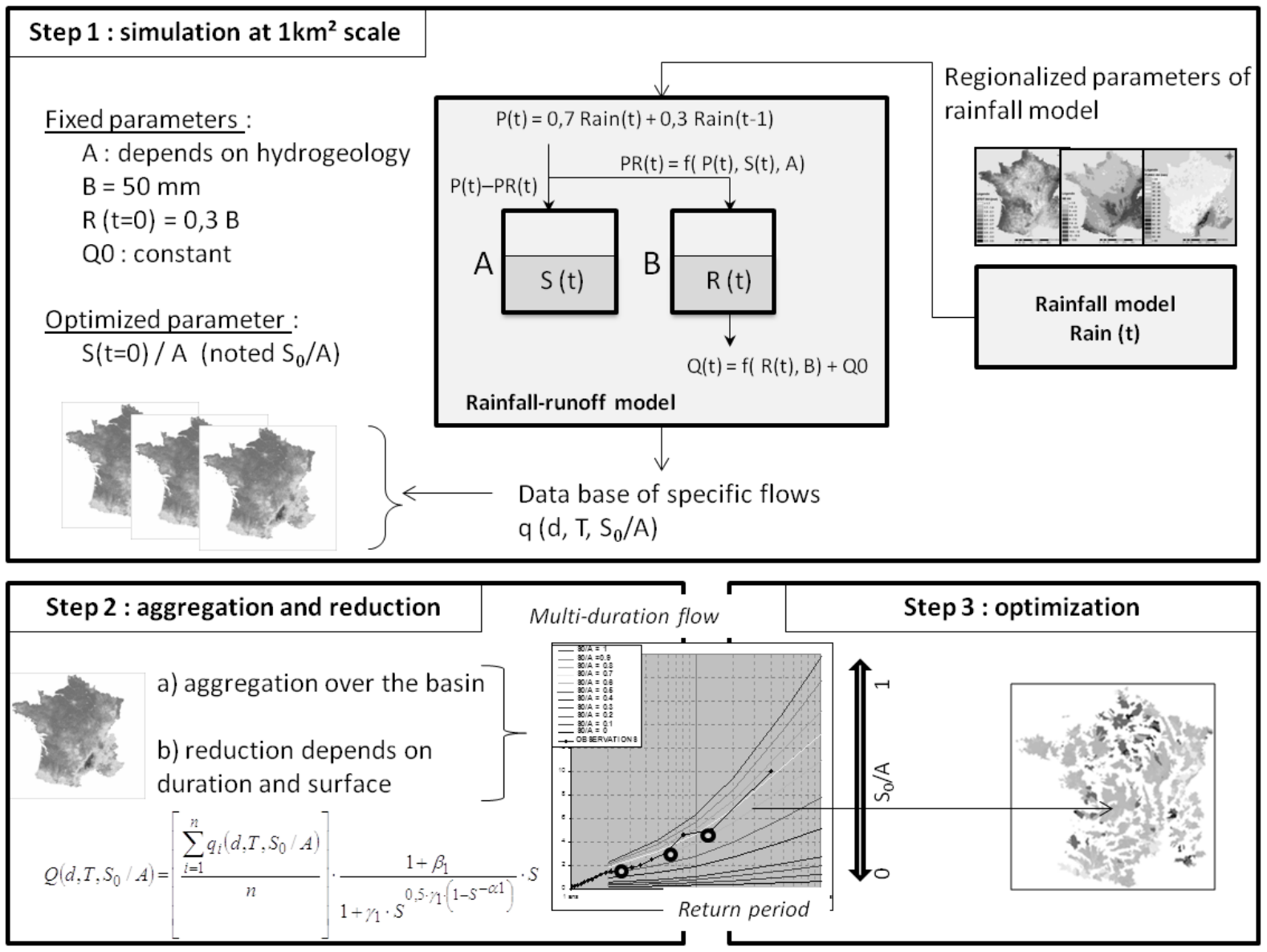

2 Figure 1: SHYREG method calibration principle

3

The first step is to generate specific flow quantiles for each $1 \mathrm{~km}^{2}$ pixel. In this way, independent hourly rainfall events are simulated at each pixel, using regionalized parameters from the rainfall generator. These hourly rainfall events are converted into independent flood events using a simple rainfall-runoff model, in which some parameters are fixed (in part because the model is being used on $1 \mathrm{~km}^{2}$ pixel).

The hydrological model is of the Irstea GR type (www://cemagref.fr/webgr/). It consists of two reservoirs and a unit hydrograph (Arnaud et al. 2011) and is used in event mode to convert the hourly rain scenarios into flood scenarios at pixel scale. After testing the different structures, we selected those that performed the best in the flood modelling of 12 small basins (each about $1 \mathrm{~km}^{2}$ area). Thus, we chose to fix most of the model parameters except the first reservoir's initial recharge level. The model's rainfall input first goes through a simple unit hydrograph that distributes the rainfall in two one-hour time steps: $70 \%$ in the first time step and $30 \%$ in the second.. The capacity of the first reservoir $A$ was set as a function of the main hydrogeological classes determined according to the territory (Aubert et al. 2013). The capacity of reservoir $B$ was set at 50 $\mathrm{mm}$ (during the summer) and at $100 \mathrm{~mm}$ (during the winter), and its initial recharge level $R$ at $30 \%$ of $B$ 's capacity. Reservoir $B$ is the second routing function after the unit hydrograph for modelling transfer occurring on $1 \mathrm{~km}^{2}$ pixels. Reservoir $A$ 's initial recharge level $\left(S_{0} / A\right)$ is therefore the only variable parameter (varying from 0 to 1 ). Simulations are performed for different $S_{0} / A$ values; then flood events are simulated for each of those values, at each pixel. The flood quantiles are extracted empirically from these simulated events. Base flow $\left(Q_{0}\right)$ is added to the generated flows. $Q_{0}$ 
corresponds to the estimate of mean monthly specific flow, obtained using the LOIEAU regional method for estimating water resources (Folton and Lavabre 2006, Folton and Lavabre 2007). While this value is often negligible compared to simulated flood flows, it needs to be factored in when calibrating the method, because it enables distinguishing between surface runoff and subsurface runoff, thus avoiding a calibration bias. The generated flood events are assigned to a simulation period. and analyzed empirically to calculate the flood quantile values. Since the number of events per year is known (it is one of the rainfall model parameters), there is a correspondence between the empirical frequency and the return period (in year). The flood quantiles are read directly from the empirical distribution for return periods that are 100 times shorter than the simulation period to ensure the stability of the empirical frequencies. For example, to obtain millenial quantiles, the equivalent of 100,000 years of rainfall events is simulated and the $1000 \mathrm{yr}$-quantiles are estimated by the $100^{\text {th }}$ highest value. This task is performed for each of the 550,000 pixels that cover the metropolitan France. The spatial variability of specific flows for a same duration, a same return period and a same $S_{0} / A$ value is mainly caused by the variability of simulated rainfall, then by the size of reservoir $A$, and finally, to a lesser extent, by the base flow $Q_{0}$. The second step is to calculate the flood quantiles at gauged catchment outlets for different $S_{0} / A$ parameter values. For each catchment and each $S_{0} / A$ value, the runoff on catchment pixels is cumulated. This value is then reduced by a function that depends on catchment surface area and mean flow duration (Aubert 2012, Fouchier 2010). This function allows factoring in areal reduction of rainfall and flood routing simultaneously. It is represented by equations (1) and (2):

$$
Q\left(d \geq 24 h, T, \mathrm{~S}_{0} / \mathrm{A}\right)=\overline{q_{d}} \cdot f_{1}(S) \cdot S
$$

with the terms $\overline{q_{d}}=\left[\frac{\sum_{i=1}^{n} q_{i}\left(d, T, \frac{S_{0}}{\mathrm{~A}}\right)}{n}\right]$ and $\quad \mathrm{f}_{\mathrm{i}}(S)=\frac{1+\beta_{i}}{1+\gamma_{i} \cdot S^{0,5} \gamma_{i} \cdot\left(1-S^{\alpha_{i}}\right)} \cdot S$

where $n$ is the number of $1 \mathrm{~km}^{2}$ pixels contained on the catchment; $S$ is catchment area in $\mathrm{km}^{2}$; $Q\left(d, T, S_{0} / A\right)$ is mean flow (of duration $d$ and return period $T$ ) calculated at the catchment outlet $(d=0$ for peak flow) for a given $S_{0} / A$ value; $q_{i}\left(d, T, \mathrm{~S}_{0} / \mathrm{A}\right)$ is the mean flow of duration $d$ and return period $T$, simulated for a catchment pixel ( $d=0$ for peak flow) for a given $S_{0} / A$ value. Parameters $\alpha_{1}$, $\alpha_{2}, \beta_{1}, \beta_{2}, \gamma_{1}$ and $\gamma_{2}$ are assumed constant over the metropolitan France and were calibrated in a preliminary study with calibration data. This study showed that calibration period does not influence parameter's value estimated over the French territory and $\alpha_{1}, \alpha_{2}, \beta_{1}, \beta_{2}, \gamma_{1}$ and $\gamma_{2}$ values are fixed. In this way the $Q\left(d, T, S_{0} / A\right)$ flows are obtained for each catchment.

The areal reduction factor is modelled by the functions $f_{1}(S)$ and $f_{2}(S)$ presented in Figure 2. $f_{1}(S)$ represents areal reduction of flow averaged over more 24 hours, and $f_{2}(S)$ represents areal reduction of the difference between flow average over less than 24 hours and flow averaged on 24 hours. 


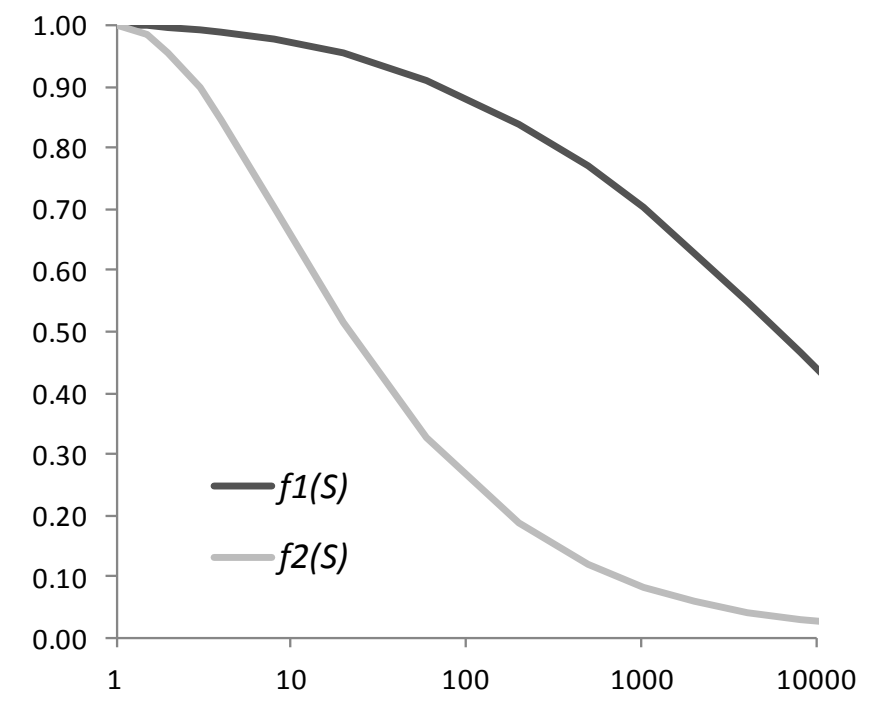

Figure 2 : representation of the areal reduction function.

The third step is the actual calibration of the method and consists in finding the $S_{0} / A$ value that minimizes the deviations between the six quantiles obtained from observations (peak flows and mean daily runoff for 2-, 5- and 10-years return periods) and the same six quantiles provided by the SHYREG method. The quantiles from observations are estimated by fitting a GEV probability distribution for which the value of the shape parameter is imposed between 0 and 0,4 . The choice of probability distribution is relatively insignificant as long as you are dealing with observated frequencies ( $T<10$ years). For each gauged catchment, then, the SHYREG method can be calibrated by optimizing a single parameter, on which the regionalization process will rely to apply the method over the entire drainage network (including ungauged environments).

Setting local parameters concerns only the rainfall yield (production), via the calibration of the $S_{0} / A$ parameter. When it is calibrated, this parameter also allows offset the assumptions made about the other parameters (fixed or regional parameter) which have been set. Since this is not a continuous method, we assumed that the rainfall events, which are generated independently, always occur in a system where the initial state is the same, and given by the parameter $S_{0} / A$.

\section{Flow data and assessment index}

\subsection{The data}

Even if the SHYREG method was designed as a multivariate approach, the present article focuses on only two flood characteristics: peak flow and daily runoff. The data analyzed are runoff series recorded at 1,172 gauging stations in the metropolitan France for which catchment areas range from 10 to $2000 \mathrm{~km}^{2}$. While these series are available in daily time steps, only 605 of them also provide instantaneous runoff series, which are usually observed over shorter periods. These stations, shown in Fig.3, were chosen within the framework of the ANR Extraflo ${ }^{2}$ project, from the national Hydro database for the most part, but also from database of Electricity de France (16 stations). They were chosen for their rating curve quality (high level of water deemed satisfactory by the observation

${ }^{2}$ The purpose of the ExtraFlo project (Extreme Rainfall and Floods), funded by the French national research agency ANR, was to establish a comparison framework of methods for estimating extreme rainfall and flood in France. 
manager) and for their observation period (long enough to provide significant statistics: more than 20 years for all stations, with a median of 40 years). Highly specific stations (heavily karstic or anthropised catchments) were excluded (Organde et al. 2013). Some of the station selection criteria are based on tests, like trends and step-changes tests, defined in article(Renard et al. 2008).

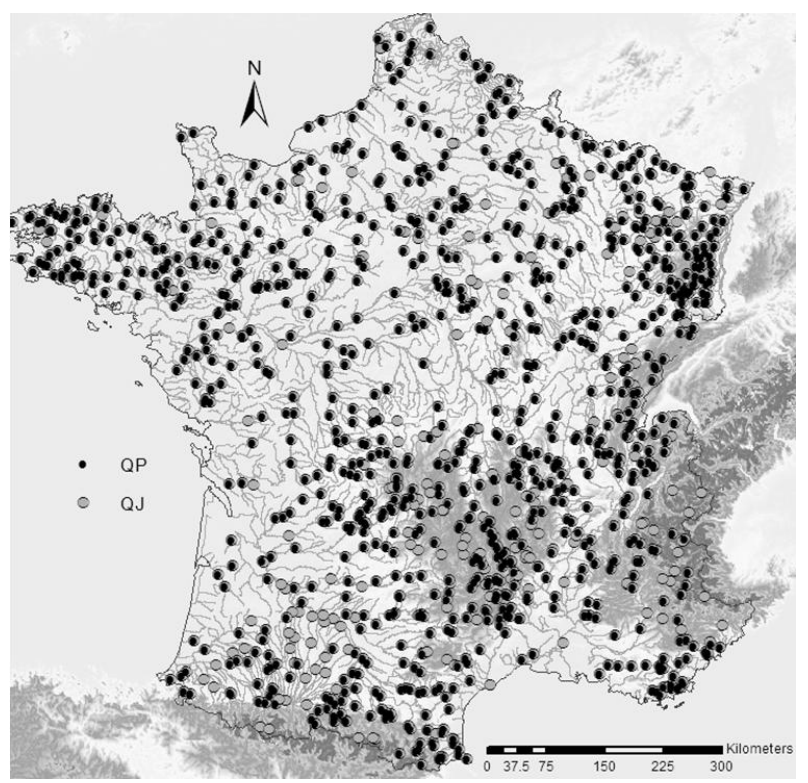

Fhgure 3: Locations of the catchment outlets studied, with gray points showing daily time steps (QJ) only a\&d black points showing instantaneous time steps $(Q P)$.

9

\subsection{Assessment index}

The framework developed for the ANR Extraflo project was used to assess the SHYREG method. This framework defines a decomposition strategy to differentiate between the calibration (training set) and validation (testing set) periods described in the following paragraph. It also defines the indexes used to assess the methods' results. A thorough description of this assessment platform is given by the article (Renard et al. 2013).

This article rapidly describes some of these indexes, which were used to assess method reliability and stability.

Two performance indexes are designed to evaluate the goodness-of-fit with particular care for the extreme part of the distribution. These indexes allow judging the reliability of a given method on a whole territory, assessing the ability of a model to assign correct exceedance probabilities for several stations. These indexes are (Fig.4 shows how these are determined):

- The index $N T$ is based on the number of quantile excesses: it verifies if the number of observation above a $T$-year quantile estimated by a given method is consistent with the empirical quantile level. The theoretical distribution of said number of observations is then identified by a binomial distribution for parameters $n$ (number of years of observation) and $1 / T$ (annual frequency of success) (Renard et al. 2013).

- The index FF, which is used e.g. by (England et al. 2003, Garavaglia et al. 2011), corresponds to the frequency a method gives for the highest observed value in $n$ years of observation. Under the reliability assumption, the theoretical distribution of this index is 


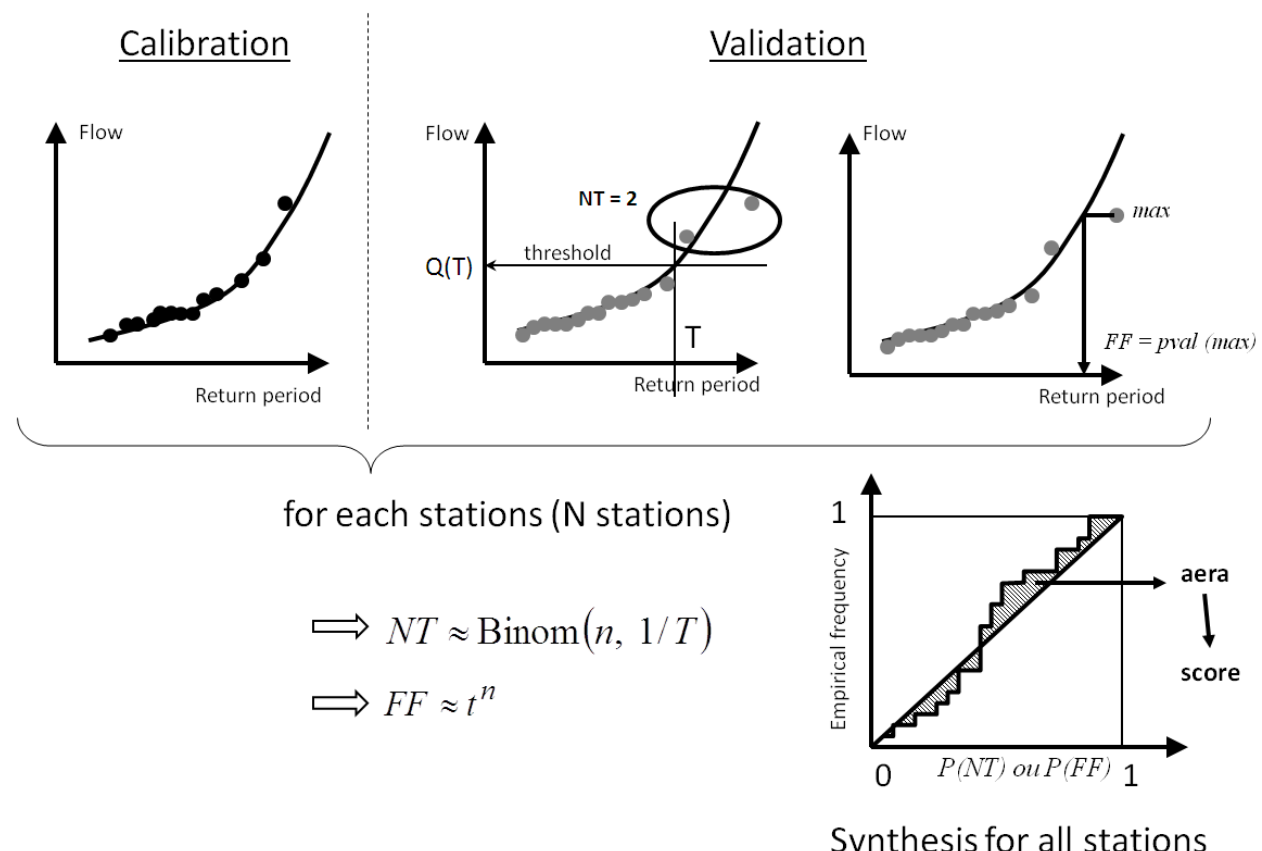

Fhgure 4: Calculation principle for reliability indexes NT and FF

First the method is calibrated on the observations from the calibration set (black curves and black dots in Fig.4). The values for the indexes $N T$ and $F F$ are then calculated based on the observations in the validation set (gray dots). By inverting the theoretical probability distributions for these index (binomial for $N T$ and beta for $F F$ ), their probability of occurrence are obtained, $P(N T)$ and $P(F F)$, which should follow a uniform probability if the model is reliable. The reliability of the methods is determined by the deviation between the observed probability and the theoretical probability for the indexes $N T$ and $F F$ (the graph at the bottom of Fig.4). If the frequency distributions for the $P(N T)$ and $P(F F)$ align around the bisector -ie- close to a uniform law, then the method has no systematic bias. Graphical analysis shows the nature of the biases of the method. If the distribution is below the bisecting line, then the method tends to underestimate flood quantiles; whereas if it is above, then the method tends to overestimate flood quantiles on the studied territory. When the distribution appears as a 'S' curve, it means that the method is over-parameterized.

The stability of a frequency analysis method is linked to its ability to produce similar results when it is calibrated on different samples. In order to determine the stability of a method, a model calibration is performed independently on two different data samples ( $C 1$ and $C 2$ ) leading to two quantile estimations $\left(Q_{C 1}\right.$ et $\left.Q_{C 2}\right)$. Then the relative deviations between the quantiles for different return periods $(T)$ and at each site (i) can be estimated (equation (3)) (Garavaglia et al. 2011).

$$
\operatorname{SPAN}^{(i)}(T)=2 \cdot \frac{\left|Q_{C 1}^{(i)}(T)-Q_{C 2}^{(i)}(T)\right|}{Q_{C 1}^{(i)}(T)+Q_{C 2}^{(i)}(T)}
$$

A stable method is then characterized by an index SPAN close to 0 . 
The graphical analysis of the different indexes can be synthesized by calculating scores, which are based on calculations of the area between the observed distribution and the theoretical distribution (bisecting line) for each index (Fig.4). By standardizing this area, it is possible to make all scores vary between 0 (poor performance) and 1 (perfect performance) (Renard et al. 2013).

\subsection{Decompositions}

To assess the method's performance, statistical decompositions were performed on the observation years. For method reliability, the observation years were split into two samples: a calibration sample consisting of a random sampling of the years used to calibrate the method, and a validation sample composed with the rest of the years. For reliability, three decompositions were performed:

- C50V50: out of 519 daily runoff series (and of 605 instantaneous runoff series) with at least 40 years (respectively 20 years) of observations, $50 \%$ of the years were used for calibration and $50 \%$ of the years were used for validation;

Because method stability could depend on the amount of data available, several decompositions were performed using sample size for both periods, over 10, 15 and 20 years. The decompositions were labelled CC_10, CC_15, and CC_20, respectively, and required gauging stations with minimum observation periods of 20,30 and 40 years, respectively. Due to the lengths of runoff series, decomposition was performed only on daily data for which the observation periods were longer. On this basis, the number of available stations was 1,122 stations with more than 20 years of data, 848 stations with more than 30 years of data, and 432 stations with more than 40 years of data.

\section{Results}

The SHYREG method's performance was analyzed by viewing the frequency distributions for $P(N T)$ and $P(F F)$ and stability index $S P A N$ and computing the corresponding scores (indicated in the graph legend). To put the results of the SHYREG method into perspective, we compared these results to those obtained with two other usual statistical models in France: the Gumbel distribution (2 parameters) and the GEV distribution (3 parameters), for which the parameters are estimated by the L-Moments method. This comparison is far from being exhaustive, and serves only to put the results into perspective compared to simple, well-known methods. First we present the results for daily flow estimates. 


\section{$1 \quad 4.1$ The method's reliability}

2 To judge the method's reliability the $F F$ and the $N T$ indexes has been used. The index $N T$ was

3 calculated for 10- and 100-year return periods (values N10 and N100). The graphs in Fig.5 show the index frequency distributions for the three models that were compared (SHYREG, Gumbel distribution and GEV distribution), obtained at the C50V50 decomposition validation stations. The index for each curve is indicated in the upper left-hand corner.
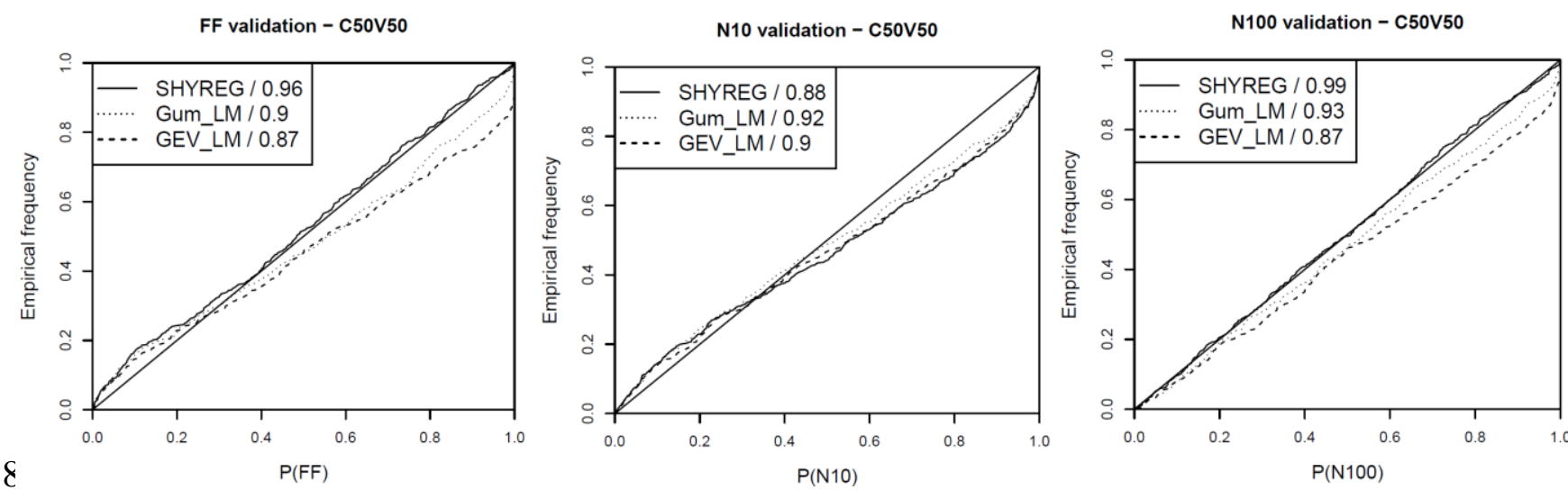

Figure 5: Frequency distribution for $P(F F)(a), P(N 10)(b)$ and $P(N 100)(c)$

10 The values of $F F$ and $N 100$ represent the capacity of the models to assign accurate frequencies to 11 extreme values. The value of N10 determines the ability to exceed rare values. In the case of extreme values, the values of SHYREG's reliability index are very good. The two statistical models also perform well. The frequency distribution analysis of $P(F F)$, however, reveals a tendency of the purely statistical models to underestimate the frequency of the highest records in some cases (curve below the bisecting line). Assigning a $P(F F)$ of 1 is particularly problematic, since the record observed over the validation period is deemed "improbable". This was the case for 19 stations out of the 519 analyzed, when calibrating a GEV distribution based on the calibration sample. The GEV distribution has three calibration parameters, so it can be calibrated as closely as possible to the empirical distribution (and presents the risk of over-fitting). If the empirical distribution has no extreme values, it is likely that the proposed extrapolation will underestimate the probability of observing a high value. The extrapolation to rare frequencies proposed by the SHYREG method, on the other hand, is linked directly to the extrapolation proposed by the rainfall model, in combination with the rainfall-runoff model's saturation capacity. This characteristic seems preferable in proposing a more reliable extrapolation to extreme values.

\subsection{The method's stability}

Method stability was determined by analyzing the distribution of the index SPAN, estimated from the quantiles for the 10-, 100- and 1,000-year return periods (SPAN10, SPAN100 and SPAN1000).

30 The graphs in Fig.6 show the results obtained using two 20-year calibration periods (decomposition 31 CC_20). 

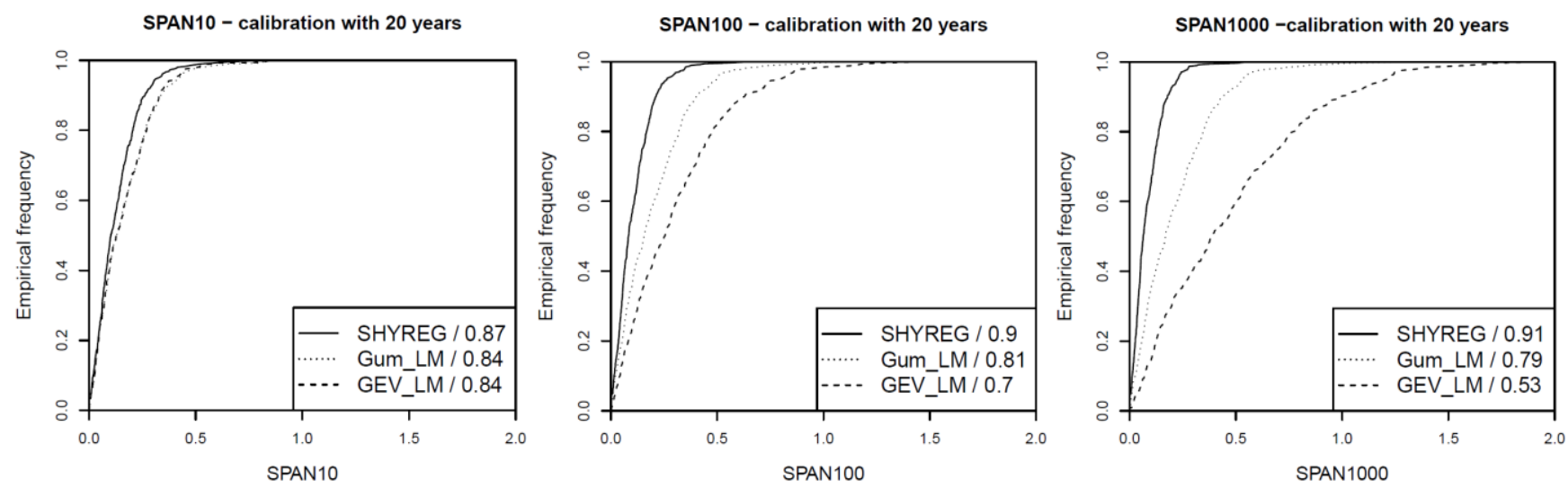

Figure 6: Frequency distribution for index SPAN computed from the quantiles for 10-year (a), 100-year

(B) and 1,000-year (c) return periods.

4 The methods are generally less stable when dealing with the longest return periods. The instability

5 is even greater for the methods that are calibrated using a larger number of parameters. For instance,

6 fitting a GEV distribution (3 parameters) is less stable than fitting a Gumbel distribution (2

7 parameters). For the SHYREG method, fitting the method at site relies only on the calibration of a

8 single parameter that represents catchment production in a simplified way. It is clearly

9 representative of average catchment behaviour and will be weakly influenced by the calibration

10 sample. This is also why calibrating this parameter is based on fit of current flood quantiles $(\mathrm{T}=2$,

115 and 10 years). The extrapolation stability is then linked to the stability of both the rainfall

12 generator and the rainfall-runoff relationship. Rainfall generator stability was also analyzed under

13 the ANR Extraflo project. The stability of the SHYREG method's rainfall generator was shown to

14 be especially stable (Carreau et al. 2013), in agreement with the results of (Muller et al. 2009)

15 showing that the confidence intervals for the quantiles provided by the hourly rainfall generator are

16 relatively narrow.

\subsection{Sampling effect}

19 The SHYREG method's performances are analyzed with respect to the size of period sampling. The

20 reliability is compared on the C33V66, C50V50 and CVrecord decompositions presented above.

21 The stability is tested on decompositions CC_10, CC_15 and CC_20 to analyze the impact of

22 calibration sample size on the method's stability. To put these results into perspective, we present

23 only the results obtained with a Gumbel distribution fit. The choice of a Gumbel distribution has

24 been motivated by its better stability than that of GEV distribution and so, more challenging. 
FF SHYREG - sampling effect (validation)

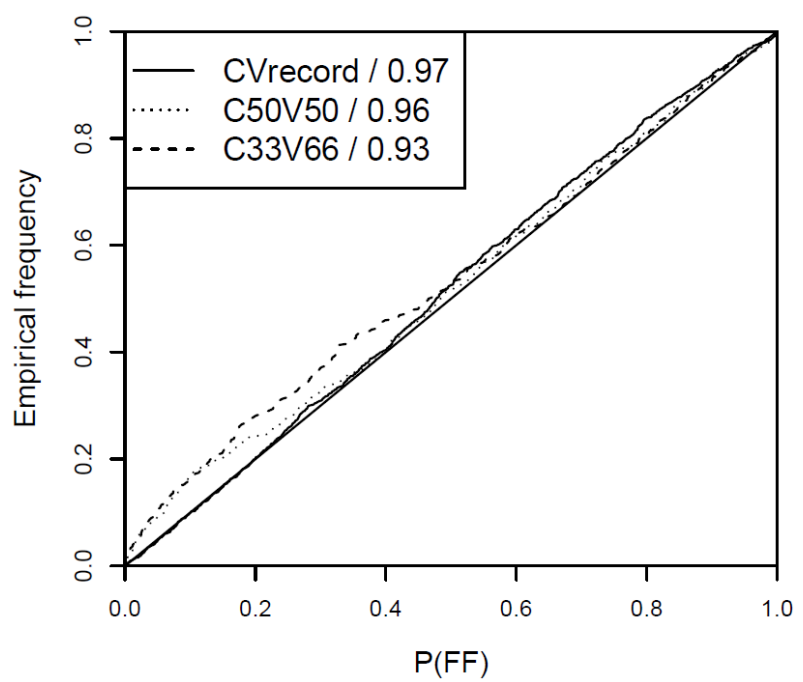

1

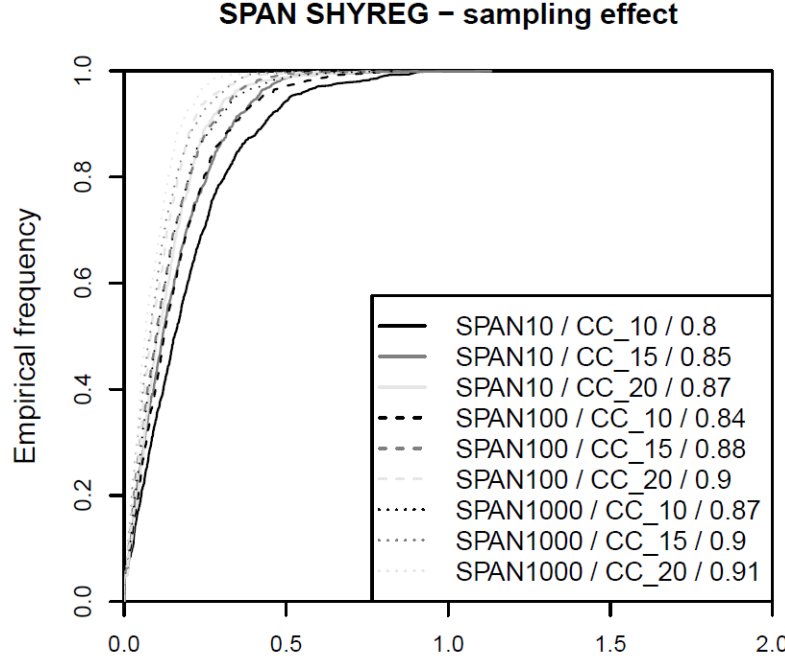

SPAN
FF GUMBEL - sampling effect (validation)

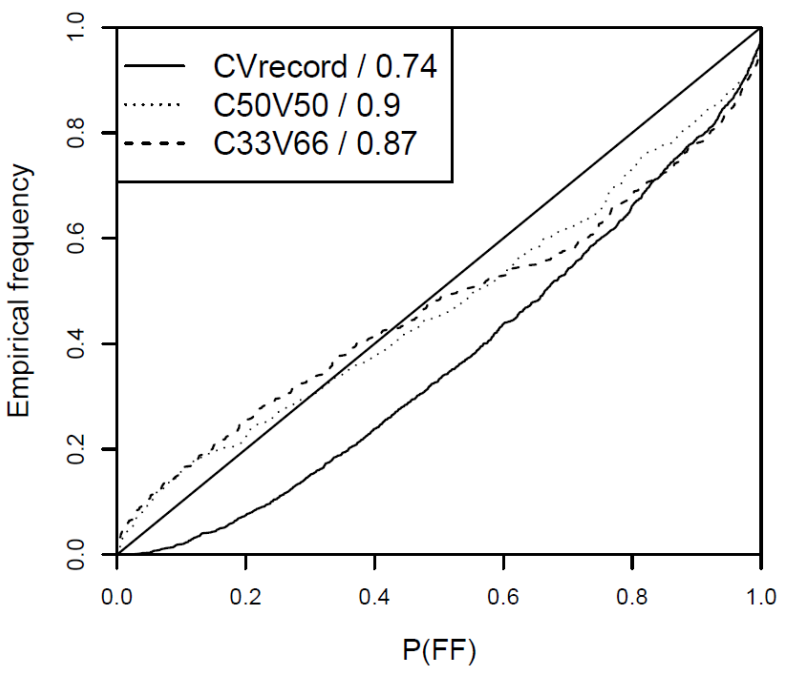

SPAN GUMBEL - sampling effect

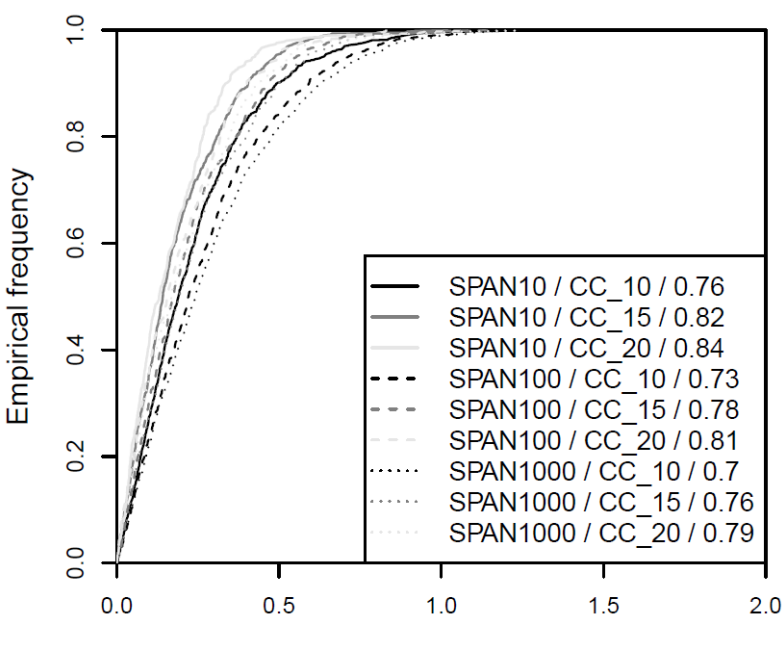

SPAN

Figure 7: Sampling effect on the SHYREG method's performance and comparison with that of a Gumbel dAstribution.

5 Graph (a) in Fig.7 shows that the SHYREG method is not highly sensitive to the sampling period.

6 However, we must remember that in the case of the C33V66 decomposition, we have at least 13

7 years of calibration. The most interesting result is that the method has very good reliability index

8 even if the highest value is systematically omitted from the calibration sample. The absence of such

9 a record value in the calibration sample does not create a bias in the SHYREG method's extreme

10 value estimates. This is particularly significant given of the problems that can occur with

11 measurement of extreme flood data. The analysis of (b) in Fig.7 shows that a 2-parameter

12 distribution is much more sensitive to sampling, in particular when the highest value is omitted

13 from the sample. In that case, the model almost systematically underestimates the probability of

14 extreme flood occurrence. SHYREG provides more "predictive" extrapolations. This is linked to

15 the method's heavy reliance on regional rainfall data. Since the rainfall-runoff relationship is not

16 highly sensitive to knowledge of an extreme event (the rainfall-runoff model must be parameterized

17 independently of rainfall), the method has the capability to calibrate itself correctly despite the

18 absence of extreme values in the calibration sample. This is not the case for a method that use only

19 on runoff data, especially if it is calibrated at site and if it have a lot of parameters. That is why 
1 methods that use only on runoff must factor in regional runoff data (Darlymple 1960, Hosking and

2 Wallis 1997, Ribatet et al. 2007, Ouarda et al. 2008).

3 The sampling effect on stability is logical. Graphs (c) and (d) in Fig.7 show that longer the calibration period is, greater the stability is. The length of the calibration period has no real impact in the SHYREG's method, whatever the return period. For a Gumbel distribution, stability decreases when the return period increases and when the calibration period decreases. These results are even more marked with the 3-parameter distribution as GEV.

\subsection{Multivariate approach}

The SHYREG method is a multivariate method. For the same calibration and simulation, it provides flood quantiles for different durations from peak flow to 3-day flood volumes. The radar charts in

12 Fig. 8 summarize the scores obtained when both daily flows QJ (left) and peak flows QP (right). The outer-most curves show the best performance.
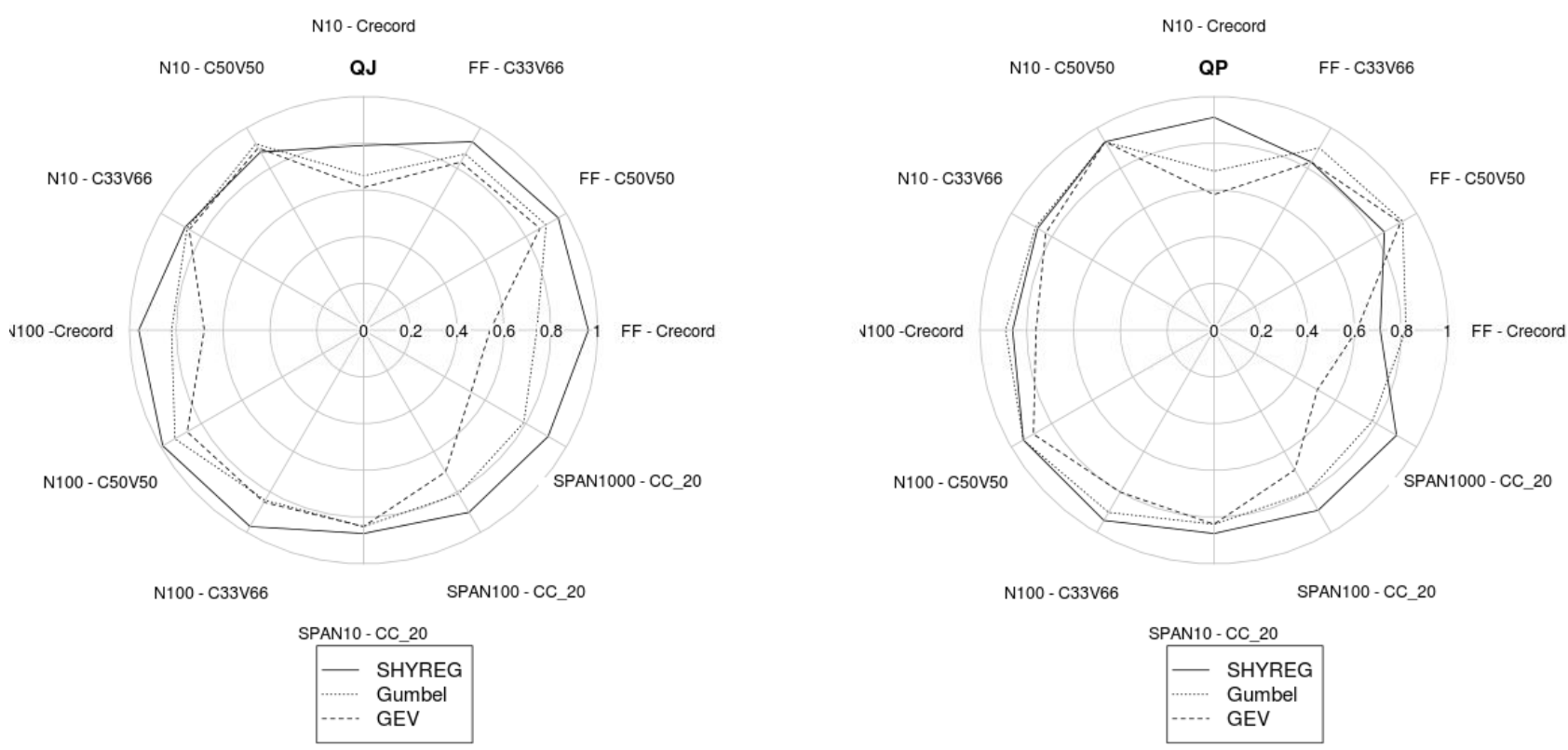

FGgure 8: Method's score for daily flow and peak flow estimates.

17 For peak flows, the observations of mean daily flows remain valid. However, there is a slight 18 decrease in SHYREG performance for reliability criteria estimates, because the method slightly overestimates (by roughly 5-10\%). The method shows the same stability characteristics. The peakflow results for a statistical distribution (Gumbel or GEV) are similar to those for daily flows.

The results obtained here show that the method performs well with respect to its capacity to estimate flood quantiles for different durations. This is especially noteworthy because the performance of multivariate approaches tends not to be as good as that of univariate approaches where the parameters can be calibrated for each variable of interest (Gräler et al. 2013).

\subsection{Sensitivity to the modelling hypothesis}

28 The stability characteristics of the SHYREG method are linked to the fact that the rainfall-runoff model has few parameters. Calibrating the method relies on a single parameter, $S_{0} / A$. The other parameters used in rainfall-runoff models are either fixed values, or regional parameters that are 
prescribed by the method's modelling hypotheses and therefore not considered as at-site fitting parameters. To see the impact of modelling hypotheses on the method's results, different model versions are tested. To avoid overloading the analysis, we present only the tests with a potential impact on the method's asymptotic behaviour. These tests involve the parameters associated with the method's equifinality issues as presented by (Aubert 2012, Aubert et al. 2013).

The table below lists the hypotheses that were tested for the regionally estimated parameters. In particularthe parameterization of the production reservoir $A$, which can influences the asymptotic behaviour of the method towards extreme values, is discussed.

11

\begin{tabular}{llll}
\hline Test & Value of $A$ & Drainage of $A$ & $Q_{0}$ \\
\hline Final & Hydrogeology dependent & No drainage & Factored in \\
Variant 1 & Max (200 mm,PJ100) & No drainage & Factored in \\
Variant 2 & Max (200 mm,PJ100) & With drainage & Factored in \\
Variant 3 & Max (200mm,PJ100) & With drainage & Not factored in $Q_{0}=0$ \\
\hline
\end{tabular}

Dable 1. Summary of hypotheses tested for regional parameters of rainfall-runoff model.

13

- The value of reservoir $A$ : In one version of the approach, the maximum capacity of production reservoir $A$ was parameterized as a function of the 100-year daily rainfall ( $P J 100$ in $\mathrm{mm}$ ) (Organde et al. 2013). This value was optimized for each catchment on data of calibration years and a link with the hydrogeology was established. The value of reservoir $A$ was then regionalized as a function of the hydrogeology. This process is only weakly influenced by station sampling, because the hydrogeology link is relatively weak and serves only to establish key value classes according to hydrogeologically homogeneous regions. Still, it does help to enhance the method's performance, in particular on catchments in Northern France (Aubert 2012) with high retention capacity.

- Drainage of reservoir $A$ : there is no drainage of reservoir $A$, and this could result in its saturation during an event. A version taking drainage into account was tested, with drainage parameterized as being proportional to the capacity of $A$ (Organde et al. 2013). This relation avoids regionalizing an additional parameter.

- Factoring in base flow $Q_{0}$ : the method did not initially take base flow into account. When the method was adapted to a wider range of hydrological conditions, a base flow was factored in to improve method calibration. Improvements were subsequently observed, especially on catchments that are heavily influenced by subsurface exchange and snow melt (Aubert 2012).

The radar charts in Fig.9 provide a synthesis of SHYREG's scores as a function of the different rainfall-runoff modelling hypotheses. 


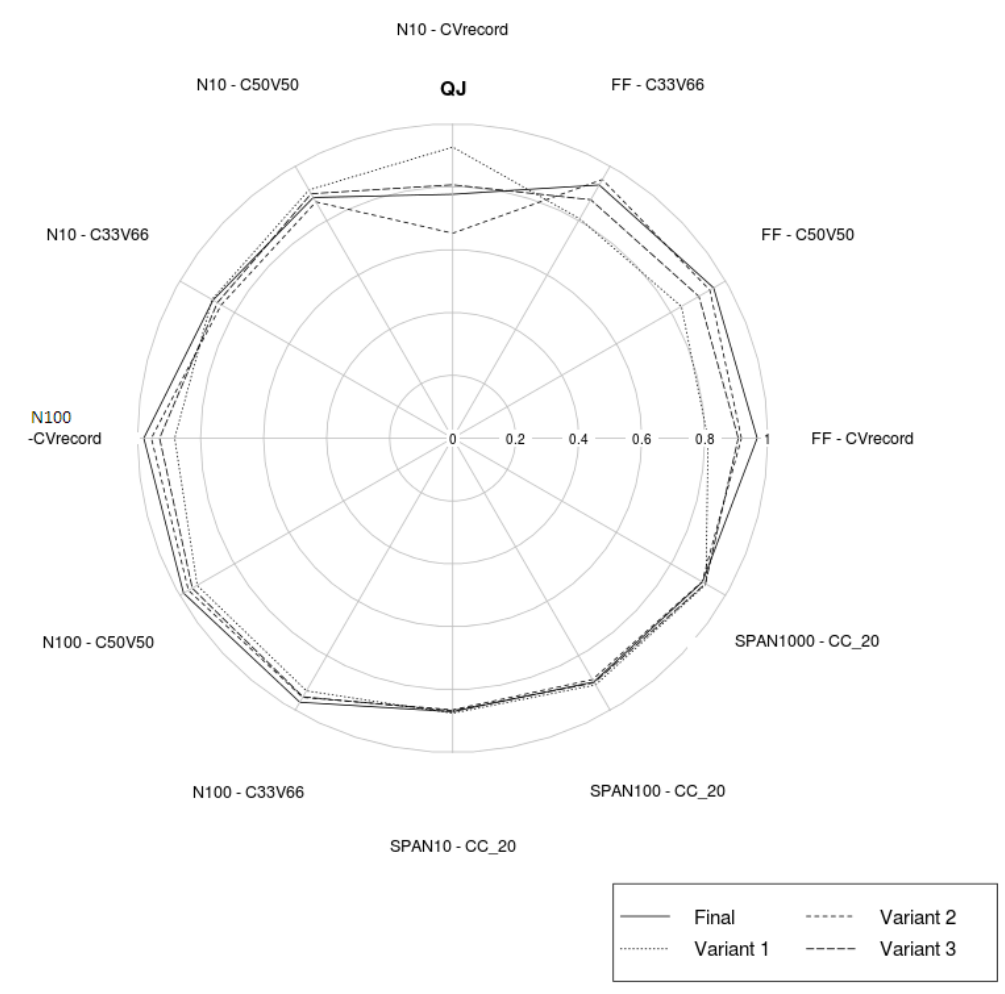

Figure 9: SHYREG method's score for different rainfall-runoff modelling hypotheses used in the method.

3 The modelling hypotheses have a moderate impact on SHYREG's performance. The impact mainly

4 concerns the extreme values, seen through the evolution of the $F F$ score. The $N 10$ and N100 values

5 are less sensitive to the modelling hypotheses. However, the method's stability does not change whatever the hypothesis made. The method's calibration parameter $S_{0} / A$ takes on different 'optimal' values as a function of the hypotheses tested on the rainfall-runoff model's production. These values serve to provide identical estimates for the common values ( $T<10$ years) used to calibrate the model. On the other hand, extrapolations to extreme values can be more variable, although certain configurations can compensate. For instance, Variant 2 is able to reach the performance of the Final model by introducing a drainage process into the production reservoir. Variant 1 resulted in a smaller average capacity for reservoir $A$ than the initial model, causing the reservoir to saturate more rapidly. Adding a drainage process helps compensate for the saturation. Variant 3 serves to confirm the advantage of taking into account an initial flow, even if the gain is relatively small. So here, we are verifying that SHYREG's chosen modelling hypotheses have no impact on the method's stability, and a relatively small impact on its reliability.

\section{Discussion}

It is difficult to validate flood frequency analysis methods at only one station, due to the lack of observation data on extreme values. The original methodology used in this article allows assessing methods by compiling statistics over a large number of stations. Comparison with other standard hydrological approaches (fitting a probability distribution on annual maximum flows) also helps to put into perspective the performance of the SHYREG method. The methods are first assessed for their reliability. If the values of the reliability indexes are weak then the method is unreliable, because of systematic biases for example. If the reliability criteria are good, you cannot affirm that the method is reliable but only that it is not incorrect. This is due to the criteria that cannot detect random biases in a method (it can only detect systematic biases). So, in the case of random biases, 
good reliability value can be due to hazard. However, a method containing this type of random bias will be detected by its poor stability performance.

The SHYREG method has good reliability criteria. Among methods with good reliability criteria, the method with the greatest stability is to be preferred. This is also the case for SHYREG method, where the good stability characteristics are due to the small number of parameters (only one parameter) it requires and the type of approach. It would appear that an approach based on rainfall data use leads to particularly relevant flood flow extrapolation.

The SHYREG method was also assessed within the larger framework of the ANR Extraflo project, where additional statistical methods, e.g. regional ones, were compared. It emerged that only approaches that take regional data into account can lead to reliability and stability results close to those of the SHYREG method (Kochanek et al. 2013). The benefits of these RFFA are now emphasized by many authors. These results of ANR Extraflo project showed that SHYREG method has the same benefits as RFFA.

Despite its good performance, the method needs improvement. In particular, the use of a unique runoff reduction factor for the whole French territory is a strong assumption and need to be improved in the future. In this way, we are working to impose coefficients by large hydro-climatic areas.

\section{Conclusion}

This study demonstrates the performance of an extreme flood estimation method by simulation. The SHYREG method is designed to analyze flood flows of all durations (from peak flow to 3-day flood volumes) based on the calibration of a single parameter characterizing catchment production. The SHYREG method was applied to French territory and regionalized; it is currently in operational use to estimate extreme flood flows (Aubert et al. 2013).

Split-sample test procedures were used to assess the method based on its "predictive" performance. Statistical reliability and stability criteria were calculated for different sampling configurations. To put the results into perspective, they were compared with those from standard statistical models in use that are based on parametric probability distributions fitted on peak annual flow data (Gumbel distribution and GEV distribution).

The results show that the SHYREG method is highly stable. The method's stability is linked to the fact that it relies on the regional statistical features of the data and on a simple rainfall-runoff model. Calibrating the method on a catchment is done using a single parameter. The other parameters are set a priori on a regional basis, independently of the rainfall data that is available for the catchment under consideration.

The method's reliability indexes have very good values, better than those found with the standard statistical methods that were tested. A supplementary study showed that to obtain reliability criteria as good as SHYREG's, you would need to use a regional statistical distribution (Kochanek et al. 2013). The method's reliability is linked to the type of approach, which proposes an estimation of extreme flows based on regional extreme rainfall data. This type of rainfall data as provided by the 
method was also found to be reliable and stable (Carreau et al. 2013). It was also demonstrated that the method enables relevant "predictive" estimates, e.g., by assigning correct return periods to the

\section{Acknowledgments:}

This work was partially supported by the French Research Agency (ANR) through the project EXTRAFLO (https://extraflo.cemagref.fr/). The HYDRO database (Ministry of environment) and EDF are gratefully acknowledged for providing the data. The authors thank ANR Extraflo project members for their contribution to the evaluation framework development.

\section{References:}

ARNAUD, P., FINE, J.-A. and LAVABRE, J. 2006. An hourly rainfall generation model adapted to all types of climate. Atmospheric Research, 85(2), 230-242.

ARNAUD, P. and LAVABRE, J. 1999. Using a stochastic model for generating hourly hyetographs to study extreme rainfalls. Hydrological Sciences Journal, 44((3)), 433-446.

ARNAUD, P. and LAVABRE, J. 2002. Coupled rainfall model and discharge model for flood frequency estimation. Water Resources Research, 38(6).

ARNAUD, P. and LAVABRE, J., 2010. Estimation de l'aléa pluvial en France métropolitaine. QUAE, Paris. Update Sciences \& Technologies, 158 pages.

ARNAUD, P., et al. 2011. Sensitivity of hydrological models to uncertainties in rainfall input. Hydrological Sciences Journal, 56(3), 397-410.

ARNAUD, P., et al. 2008a. Regionalization of an hourly rainfall generating model over metropolitan France for flood hazard estimation. Hydrological Sciences Journal, 53(1), 34-47.

ARNAUD, P., et al. 2008b. Regionalization of an hourly rainfall model in French territory for rainfall risk estimation. Hydrological Sciences Journal, 53(1), 21p.

AUBERT, Y., 2012. Estimation des valeurs extrêmes de débit par la méthode SHYREG : réflexions sur l'équifinalité dans la modélisation de la transformation pluie en débit. . Université Paris VI.

AUBERT, Y., et al., Rainfall frequency analysis using a hourly rainfall model calibrated on weather patterns : application on Reunion Island. In: ABSTRACTS, G. R., ed. EGU General Assembly 2014-7220, 2014 Viennes (Austria), 1.

AUBERT, Y., et al. 2013. La méthode SHYREG débit, application sur 1605 bassins versants en France Métropolitaine. Accepted Hydrological Sciences Journal.

BLAZKOVA, S. and BEVEN, K. 2004. Flood frequency estimation by continuous simulation of subcatchment rainfalls and discharges with the aim of improving dam safety assessment in a large basin in the Czech Republic. Journal of Hydrology, 292(1-4), 153-172.

BOUGHTON, W. and DROOP, O. 2003. Continuous simulation for design flood estimation-a review. Environmental Modelling \& Software, 18(4), 309-318.

CADAVID, L., OBEYSEKERA, J. T. B. and SHEN, H. W. 1991. Flood frequency derivation from kinematic wave. Journal of Hydraulic Engineering, 117(4), 489-510.

CANTET, P. and ARNAUD, P. 2014. Extreme rainfall analysis by a stochastic model: impact of the copula choice on the sub-daily rainfall generation. Stochastic Environmental Research and Risk Assessment, 28(6), 1479-1492.

CANTET, P., BACRO, J.-N. and ARNAUD, P. 2010. Using a rainfall stochastic generator to detect trends in extreme rainfall. Stoch Environ Res Risk Assess, 25(3), 429-441.

CARREAU, J., et al. 2013. Extreme rainfall analysis at ungauged sites in the South of France : comparison of three approaches. Journal de la Société Française de Statistique, 154(2), 119-138. 
CASTELLARIN, A., et al., 2012. Review of applied statistical methods for flood frequency analysis in Europe : WG2 of COST Action ESO901.

CERNESSON, F., LAVABRE, J. and MASSON, J.-M. 1996. Stochastic model for generating hourly hyetographs. . Atmospheric Research, $\mathrm{n}^{\circ}$ 42, 149-161.

CHOW, V. T., MAIDMENT, D. R. and MAYS, L. W., 1988. Applied hydrology. New-York: McGraw-Hill.

COLES, S., 2001. An introduction to Statistical Modeling of Extreme Values. ed. Springer-Verlag, Heidelberg, Germany.

DARLYMPLE, T. 1960. Flood-frequency analysis. Water Supply Pap., 1543A - US Geol Surv.

EAGLESON, P. S. 1972. Dynamics of flood frequency. Water Resources Research, 8(4), 878-898.

ENGLAND, J. F., JARRETT, R. D. and SALAS, J. D. 2003. Data-based comparisons of moments estimators using historical and paleoflood data. Journal of Hydrology, 278(1-4), 172-196.

FOLTON, N. and LAVABRE, J. 2006. Regionalization of a monthly rainfall-runoff model for the southern half of France based on a sample of 880 gauged catchments. IAHS Publication Large Sample Basin Experiments for Hydrological Model Parameterization: Results of the Model Parameter Experiment MOPEX, vol. 4, 264-277.

FOLTON, N. and LAVABRE, J. 2007. Approche par modélisation pluie-débit pour la connaissance régionale de la ressource en eau: application à la moitié du territoire français. Houille-Blanche, $n^{\circ} 03-2007$, 64-70.

FOUCHIER, C., 2010. Développement d'une méthodologie pour la connaissance régionale des crues. . Université Montpellier II Sciences et techniques du Languedoc.

GARAVAGLIA, F., et al. 2011. Reliability and robustness of rainfall compound distribution model based on weather pattern sub-sampling. Hydrology and Earth System Sciences, 15(2), 519-532.

GRÄLER, B., et al. 2013. Multivariate return periods in hydrology: a critical and practical review focusing on synthetic design hydrograph estimation. Hydrology and Earth System Sciences, 17(4), 1281-1296.

GUILLOT, P. and DUBAND, D. 1967. La méthode du Gradex pour le calcul de la probabilité des crues à partir des pluies. I.A.S.H., Publication, 84.

HOSKING, J. R. M. and WALLIS, J. R. 1993. Some statistics useful in regional frequency analysis. Water Resour. Res., 29(2), 271-281.

HOSKING, J. R. M. and WALLIS, J. R. 1997. Regional frequency analysis: an approach based on L-moments. Cambridge University Press.

JAVELLE, P., et al. 2010. Flash flood warning at ungauged locations using radar rainfall and antecedent soil moisture estimations. Journal of Hydrology, 394(1-2), 267-274.

KATZ, R. W., PARLANGE, M. B. and NAVEAU, P. 2002. Statistics of extremes in hydrology. Advances in Water Resources, 25(8-12), 1287-1304.

KLEMES, V. 1993. Probability of extreme hydrometeorological events - a different approach. In: Proceedings of the Yokohama Symposium, Extreme Hydrological Events: Precipitation, Floods and Droughts, Yokohama, Japan. IAHS Publ., 213(167-176).

KOCHANEK, K., et al. 2013. A data-base comparison of flood frequency analysis methods used in France. Accepted Natural Hazards and Earth System Sciences, 20 pages.

KUMARASWAMY, P. 1980. A generalized probability density function for double-bounded random processes. Journal of Hydrology, 46(1-2), 79-88.

LANG, M. and LAVABRE, J. 2007. Estimation de la crue centennale pour la prévention des risques d'inondations. Editions Quae.

LAVABRE, J., et al., Crue de projet ou cote de projet ? Exemple des barrages écrêteurs de crue du département du Gard. . ed. Colloque CFBR-SHF: "Dimensionnement et fonctionnement des évacuateurs de crues», 2009 Lyon, 20-21 janvier 2009.

LAVABRE, J., et al. 2010. Crues de projet ou cotes de projet ? Exemple des barrages écrêteurs de crue du département du Gard. La Houille Blanche, n²-2010, 58-64.

LI, J., et al. 2014. An efficient causative event-based approach for deriving the annual flood frequency distribution. Journal of Hydrology, 510(0), 412-423.

LLAMAS, J. 1993. Hydrologie générale principes et applications. $2^{\circ}$ édition, Gaëtan Morin éditeur, Paris, 527 pages. 
MARGOUM, M., et al. 1994. Estimation des crues rares et extrêmes : principes du modèle AGREGEE. Hydrologie continentale, 9(1), 85-100.

MERZ, R. and BLÖSCHL, G. 2005. Flood frequency regionalisation-spatial proximity vs. catchment attributes. Journal of Hydrology, 302(1-4), 283-306.

MULLER, A., et al. 2009. Uncertainties of extreme rainfall quantiles estimated by a stochastic rainfall model and by a generalized Pareto distribution. Hydrological Sciences Journal, 54(3), 417-429.

ONOF, C., TOWNEND, J. and KEE, R. 2005. Comparison of two hourly to 5-min rainfall disaggregators. Atmospheric Research, 77(1-4), 176-187.

ORGANDE, D., et al. 2013. Régionalisation d'une méthode de prédétermination de crue sur l'ensemble du territoire français : la méthode SHYREG. Revue des Sciences de l'Eau, 26(1), 65-78.

OUARDA, T. B. M. J., et al. 2008. Intercomparison of regional flood frequency estimation methods at ungauged sites for a Mexican case study. Journal of Hydrology, 348(1-2), 40-58.

PAQUET, E., et al. 2013. The SCHADEX method: A semi-continuous rainfall-runoff simulation for extreme flood estimation. Journal of Hydrology, 495(0), 23-37.

RENARD, B., et al. 2013. Data-based comparison of frequency analysis methods: A general framework. Water Resources Research, 49(2), 825-843.

RENARD, B., et al. 2008. Regional methods for trend detection: Assessing field significance and regional consistency. Water Resources Research, 44(8), W08419.

RIBATET, M., et al. 2007. A regional Bayesian POT model for flood frequency analysis. Stochastic Environmental Research and Risk Assessment, 21(4), 327-339.

SHEN, H. W., KOCH, G. J. and OBEYSEKERA, J. T. B. 1990. Physically based flood features and frequencies. Journal of Hydraulic Engineering, 116(4), 494-514.

STEDINGER, J. R. and TASKER, G. D. 1985. Regional hydrologic analysis: 1. Ordinary, weighted and genaralized least squares compared. Water Resources Research, 21(9), 1421-1432.

WILLEMS, P., et al. 2012. Rewiew od European simulation methods for flood-frequency-estimation. WG3: Flood frequency analysis using rainfall-runoff methods. Report of Cost Action ES0901., 66 pages.

\section{Tables:}

\begin{tabular}{llll}
\hline Test & Value of $A$ & Drainage of $A$ & $Q_{0}$ \\
\hline Final & Hydrogeology dependent & No drainage & Factored in \\
Variant 1 & Max $(200 \mathrm{~mm}, \mathrm{PJ} 100)$ & No drainage & Factored in \\
Variant 2 & Max $(200 \mathrm{~mm}, \mathrm{PJ} 100)$ & With drainage & Factored in \\
Variant 3 & Max $(200 \mathrm{~mm}, \mathrm{PJ} 100)$ & With drainage & Not factored in $Q_{0}=0$ \\
\hline
\end{tabular}

Table 1. Summary of hypotheses tested for regional parameters of rainfall-runoff model. 
2 Figure captions.

3 Figure 1: SHYREG method calibration principle

4 Figure 8 : representation of the areal reduction function.

5 Figure 3: Locations of the catchment outlets studied, with gray points showing daily time steps (QJ)

6 only and black points showing instantaneous time steps (QP).

7 Figure 4: Calculation principle for reliability parameters NT and FF

8 Figure 5: Frequency distribution for reliability criteria P(FF) (a), P(N10) (b) and P(N100) (c)

9 Figure 6: Frequency distribution for SPAN stability criteria computed from the quantiles for 10-

10 year (a), 100-year (b) and 1,000-year (c) return periods.

11 Figure 7: Sampling effect on the SHYREG method's performance and comparison with that of a

12 Gumbel distribution.

13 Figure 8: Method's score for daily flow and peak flow estimates.

14 Figure 9: SHYREG method's score for different rainfall-runoff modelling hypotheses used in the 15 method. 